\title{
Difference between Bibliometric and Grey Data. Transdisciplinary Bioeconomy Research
}

\author{
Indra MUIZNIECE ${ }^{*}$, Anna KUBULE ${ }^{2}$, Lauma $Z$ ZIHARE $^{3}$, Dagnija BLUMBERGA $^{4}$ \\ ${ }^{1-4}$ Institute of Energy Systems and Environment, Riga Technical University, Azenes iela 12/1, \\ Riga, LV-1048, Latvia
}

\begin{abstract}
This study is a follow-up to previous research on the use of a transdisciplinary approach in the analysis of factors that influence bioeconomy development and interactions between them. It is very important to consider the significance of public opinion while performing transdisciplinary research. This study integrates public opinion in the bibliometric analysis method by using grey data from information available in the public information space: mass media and social networks. The network of factors influencing the development of bioeconomy, created with the help of social network analysis method, was compared with the one obtained from bibliometric analysis of SCOPUS database in order to find out the difference between scientific tendencies and the overall atmosphere in the information space. Although the structure of these networks varies, there is a common tendency in literature to identify the following factors as the key factors in the development of the bioeconomy: research and innovations; technology; energy and energy consumption.
\end{abstract}

Keywords - Network analysis; sustainable bioeconomy; social aspects; transdisciplinarity

\section{INTRODUCTION}

Bioeconomy is rapidly becoming the backbone of economy and promotes a sustainable, knowledge and advanced technologies-based use of bioresources to produce higher valueadded products [1], [2]. Therefore, it contributes to the development and reaping of greater economic, social and environmental benefits, not only from the primary production of bioresources in agriculture, forestry and fisheries, but also from macroeconomics at the national level [3]. Biomass production cannot be increased in unlimited quantities, therefore, secondary use of bioresources in accordance with bioeconomy principles depends on the sustainable extraction of primary resources. In addition to biomass resources, agriculture, forestry and fisheries also provide non-material resources (biodiversity, ecosystem service and recreation) that can compete with or be complementary to primary resources [4]. It is expected that the development of bioeconomy will contribute to the sustainable development of economy and food security by creating new opportunities for entrepreneurship, employment and innovation, increasing the efficiency of natural resources and helping agriculture to adapt to climate change [5]. However, concrete empirical evidence on the overall economic, environmental and social impact of bioeconomy on agriculture, forestry and fisheries is still lacking [5].

There is a clear need for a transdisciplinary approach to this issue and to bioeconomy research as a whole and its further development [6], [7], involving experts from different

* Corresponding author.

E-mail address: indra.muizniece@rtu.lv 
disciplines and using not only scientifically recognized methods but also involving society and considering public opinion [8]. Golembiewski et al. (2015) pointed out the need for interdisciplinary collaboration to create innovative solutions for the growth of the bioeconomy and to develop a standardized approach to increase traceability of bioeconomy implementation [9]. In turn, Haarich et al. (2017) concluded that support is needed for the development of interdisciplinary and specific bioeconomy competences and skills not only in science but also for entrepreneurs, as well as the activities aimed at raising public awareness of potential benefits of bioeconomy [10]. Schütte (2017) emphasizes that a one-discipline approach is not appropriate for bioeconomy research because disciplines compete with each other and sustainable bioeconomy can only be applied through systemic and holistic solutions [11]. To date, there have been few studies on bioeconomy that were positioned as transdisciplinary. For example, Konstantinis et al. (2018) used the method of bibliometric analysis to evaluate the articles published in scientific databases related to bioeconomy and created a bibliometric network [12]. Muizniece et al. (2018) used a fully connected mesh network to represent the bioeconomy idea of transdisciplinarity [13]. In addition, the fundamental principles of sustainability [8], [14] - environmental, economic and social [15], [16] - must also be incorporated in order to achieve sustainable bioeconomy development.

Most research in bioeconomy has focused on natural sciences and engineering [17], but more and more researches are being conducted in the field of social sciences [18], [19]. Braun (2018) and Urmetzer et al. (2020) emphasize that public awareness of sustainability plays an important role in the development of bioeconomy [20], [21]. Regarding the social aspects in the context of bioeconomy, the research focus is set on the impact that the development of bioeconomy will have on social processes, less so - on how social processes, especially public opinion, influence the development of bioeconomy. For example, Hasenheit et al. (2016) have assessed the impact of bioeconomy on three sustainable indicators - social, economic and environmental [22]. But Falcone et al. in their study established a social influence system with regards to the production of bioproducts [23]. Vainio et al. recognize the need for research into how citizens and stakeholders understand and perceive the bioeconomy and how their participation in the bioeconomy can be improved [24]. Wohlfahrt et al. (2019) in their study emphasized that the importance of interaction between human and technological components should be acknowledged when evaluating the functioning of a bioeconomy system [25]. For his part, Schütte (2017) has raised the question of what measures are the most appropriate to promote the interaction between politics, science, industry and society, which is so important for the realization of bioeconomy [11]. These and other findings in scientific literature confirm the need to integrate social aspects in further research on bioeconomy, involving a wider range of societies and viewpoints. This is directly related to the basic principles of transdisciplinary research.

Given that different groups in society have different knowledge and interests in bioeconomy both among themselves and in comparison to other scientists [26], it is necessary to clarify and consider the views of both parties on the factors influencing the development of bioeconomy and their significance. Therefore, this study is conducted to determine what factors are important and how their influence on the development of bioeconomy is viewed in the public information space and how this view differs from that of scientists.

Social media have a significant role in creating opinion and knowledge base in society [27]. According to the agenda-setting theory, created by McCombs and Shaw (1972) [28], the mass media are creating an opinion of the audience and make society believe that some topics are true and more important than others. Social networks are also an essential part of today's mass media. Choi et al. (2016) proved that the agenda-setting theory also works on social 
media [29]. Klašnaja et al. (2017) pointed out that social media is increasingly being used to determine public opinion, and in this way, it is possible to obtain more, larger-scale and more objective data than using traditional sociological methods [30]. That is why this study uses social media to determine public opinion.

Social network analysis method is used to determine public opinion and is then followed up with heat maps and the network visualization method to represent the results. Public opinion will be determined by 22 factors influencing the development of bioeconomy, selected based on a previous study by the authors [13]. The significance of each factor is expressed in quantitative terms, which makes the comparison process more objective. Another study previously done by the authors will be used to compare a specific point of view with scientists' opinion. In this study, the opinion of scientists on the significance and interrelation of 24 factors influencing the development of bioeconomy was determined using bibliometric analysis [31]. It was concluded that, in the opinion of scientists, such factors as "bioresources", "energy, energy consumption", "technology" and "research and innovation" play an important role in the development of bioeconomy. However, no significant relationship was found with factors: "behaviour", "production", "pollution" and "infrastructure".

The obtained results will be used in future research to apply a transdisciplinary research approach identifying primary and secondary factors influencing the development of bioeconomy, which should be integrated into bioeconomy development modelling and scenario analysis in order to evaluate different bioeconomy development scenarios and tools used for bioeconomy advancement. Thus, the most effective solution for sustainable use of bioresources is found. In addition, the results of this study can be used to determine whether and how information flows on the bioeconomy and its influencing factors coincide between scientific sources and the public information space, thus answering the question: How much are trends in bioeconomy science reflected in the information space available to the general public and whether it has an impact on public opinion.

\section{Methodology}

Tendencies observed in previous research suggest that a holistic and dynamic approach, best characterized by networked structures, is needed to implement a transdisciplinary approach to research. Social network analysis method is used to determine general public's perception of bioeconomy and that of the importance of its influencing factors.

This method is commonly used in social sciences to analyse networks of individuals or organizations with common interests and their interactions using information from social networks [32]. This allows visualization of social networks, where interconnections between the actors are indicated by links and actors themselves indicated by nodes. The strength of the links and the significance of nodes is determined by weight. This study will use an atypical social network analysis approach, where the actors in the network are factors influencing the development of bioeconomy and keywords that characterize them, rather than individuals. Social networks and media will not be scanned to determine the relationship between individuals, but relationships between factors and the bioeconomy. The social network analysis method is not widely used in bioeconomy studies. For example, Giurca \& Metz (2018) conducted a social network analysis of Germany's wood-based bioeconomy, where organizations related to bioeconomy are viewed as actors [33]. Konstantinis et al. (2018) have attempted to build a social network of bioenergy stakeholders as a case study for bioeconomy [12]. In turn, Bauer et al. (2018) analysed biorefinery innovation projects in 
Sweden and networks of participating organizations using social network analysis [34]. To the authors' knowledge, no network analysis approach has been used so far to analyse factors that influence the development of bioeconomy.

\begin{tabular}{|c|c|}
\hline 1. Keyword analysis & 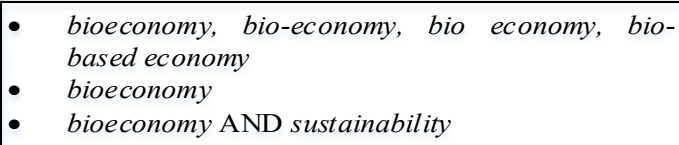 \\
\hline $\begin{array}{l}\text { 2. Bioeconomy and factor } \\
\text { describing keywords } \\
\text { analysis }\end{array}$ & $\begin{array}{ll}- & \text { bioeconomy AND keyword } 1 \text { describing factor } 1 \\
- & \text { bioeconomy AND keyword } 2 \text { describing factor } 1 \\
- & \text { bioeconomy AND keyword n describing factor } 1 \\
\text { - } & \text {.. } \\
\text { - } & \text { bioeconomy AND keyword n describing factor } 24\end{array}$ \\
\hline & Weighting of factors \\
\hline $\begin{array}{l}\text { 3. Bioeconomy and factor } \\
\text { describing keywords } \\
\text { interaction analysis }\end{array}$ & 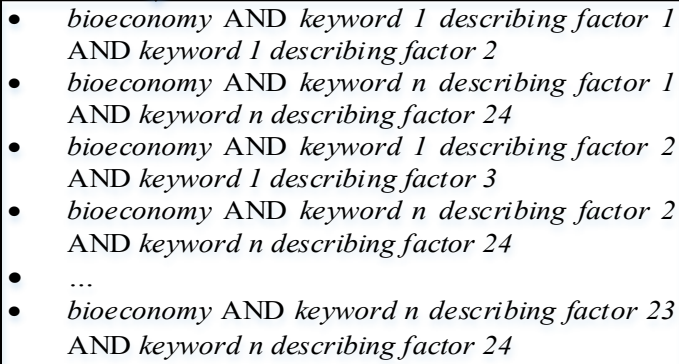 \\
\hline \multicolumn{2}{|c|}{ Adjacency matrix and weighting of factors } \\
\hline \multicolumn{2}{|c|}{ 4. Social and media network building and analysing } \\
\hline \multicolumn{2}{|c|}{$\begin{array}{l}\text { 5. Social and media network compare with similar network from the scientific } \\
\text { publications in SCOPUS database }\end{array}$} \\
\hline
\end{tabular}

Fig. 1. Research methodology.

In this case, data used for the analysis was obtained using the online tool MediaToolkit. It allows the monitoring of the information available on Internet resources, including social networks (e.g. Twitter, Instagram, Facebook) over a specific period of time by specific keywords and criteria. Because of the nature of data sources, the obtained data is considered grey data because it can include information generated by any member of society [35]. Therefore, the data obtained should not be interpreted as quantitative end results, but as an indicative source of information that needs to be processed and analysed in order for conclusions to be drawn. For an overview of the study, see Figure 1, which illustrates the research methodology. The methodology can be divided into five main steps. The number of mentions of the keywords and their combinations over a three-year period (2016-2019) was collected using MediaToolkit information. 
In the first phase of the research, information on bioeconomy was analysed by looking at 4 most common keywords [12], [26] used for its description - bioeconomy, bio-economy, bio economy, bio-based economy. Then, only for the keyword "bioeconomy" and for the combination of the two keywords "bioeconomy AND sustainability", because the essence of bioeconomy should be sustainability-oriented [1].

In the second step, the number of mentions was fixed for a combination of two keywords, one of which was "bioeconomy" in each case, and the other - one of each of the factors characterizing the study. As mentioned above, the work with 24 drivers of bioeconomy development identified in previous studies is continued in this study: land, land use; waste; wellbeing; climate change; bioresources; non-renewable fossil resources; human resources and population; research and innovation; energy and energy consumption, education and knowledge; policy; health; behaviour; technology; water; environment; consumption; financial resources; economic growth; food and feed; production; pollution; infrastructure; primary renewable resources [13], [31]. A list of keywords related to each factor can be found in Muizniece et al. (2019) research [31]. The weight of each of the factors in this system is then determined. This step identifies which of the factors in the bioeconomy context are given more prominence in the widely available information space.

The third step of the analysis is the determination of interaction between 24 factors influencing the development of bioeconomy and its importance in the context of bioeconomy. This is done by determining the information about two different factor keywords that are referred to simultaneously as "bioeconomy" at any given time, using MediaToolkit. By looking at all possible variations, an adjacency matrix of factor interactions is formed and the weight of each factor in the context of bioeconomy is determined in relation to the other factors. For the easier perception of the results, they are displayed as a heat map, with the higher value indicators in more intense colours.

In the fourth phase of the study, a network of interactions between factors that influence the development of bioeconomy was created, using the program Social Network Visualizer 2.5. and input data on interaction links from the third stage and their weight. The fourth stage was concluded with an analysis of the network structure.

In the final stage of this study, two networks obtained by monitoring and analysing data on direct and indirect significance of the 24 factors influencing the development of bioeconomy were compared - (1) from the SCOPUS scientific publications database (done in previous research [31]) and (2) from the analysis of the media and social networks in phases 1 to 4 of this study. With this, we are looking for common and different trends in relation to the bioeconomy within the scientific research compared to the flow of information in the public media and opinions expressed in social networks on the internet. Network density, structure, weights of factors and links are used to compare networks.

\section{RESUltS AND DisCUSSION}

\subsection{Media and Social and Network Analysis}

Assessing the number of mentions in the three-year period in web media and social networks for bioeconomy keywords, and separately for "bioeconomy" and "bioeconomy AND sustainability" it can be seen that the term "bioeconomy" is used primarily (see Table 1). Therefore, authors choose to put the keywords of the factors together with the keyword "bioeconomy" for the next step. The results demonstrate that nearly half of the cases where bioeconomy is mentioned is in the context of sustainability. It confirms that 
fundamental principles of the bioeconomy are considered to be an essential way of achieving goals of sustainable development. The option of MediaToolkit tool, which allows determination of sentiment ratio of the published information, shows that more than $90 \%$ of claims related to the bioeconomy have been positive, which demonstrate that publicly available information contributes to a positive social attitude towards the bioeconomy.

TABle 1. Number of Bioeconomy Mentions in Media AND Social NetworKs (2016-2019)

\begin{tabular}{lll}
\hline Keywords & Mentions & Positive sentiment ratio \\
\hline bioeconomy, bio-economy, bio economy, bio-based & 2440 & $92 \%$ \\
economy & 2373 & $92 \%$ \\
Bioeconomy & 1035 & $91 \%$ \\
bioeconomy AND sustainability & \\
\hline
\end{tabular}

In accordance with the method described above, number and weight of each of the 24 factors related to the development of bioeconomy was determined, as well as the interaction between these factors in the context of bioeconomy. Results showed that in general, the positive sentiment ratio was similar. But in each case, the numerical values of factor weights vary significantly (up to $47.1 \%$ ). Both directly related to the bioeconomy and in interaction with other factors in the context of bioeconomy, the key factors from grey data sources appear: "research and innovation", "technology", "food and feed" and "production". Then come factors "land, land use", "waste", "energy, energy consumption", "education and knowledge", "policy" and "environment". The question of the relevance of the factor "bioresources" is still open, because it has the largest difference in weights, although it is particularly important in relation to the bioeconomy.

Analysing the results on the interaction of factors in the context of the bioeconomy, it can be concluded that the strongest link is between the factors "research and innovation" and "technology" (1190 mentions in 3 years). Both of these factors are also leading factors that are mentioned in relation to the bioeconomy and in interaction with other factors. In order to select only significant interaction links, it is assumed that the interaction of factors is considered relevant if there have been at least 100 common mentions over 3 years. No direct links were found in the context of bioeconomy for five factors: "wellbeing", "climate change", "non-renewable fossil resources", "behaviour", "primary renewable resources". Based on these results, these factors are not included in the network of factors influencing the development of bioeconomy.

The network of interactions between factors affecting the development of bioeconomy resulting from the analysis of the media and social networks (Fig. 2) according to topology is similar to the partial mesh network. All nodes are connected directly or indirectly (through other points). It has no distinct central point and the interconnection network is dense. This means that this type of interaction network is stable and minor changes in one of its parts do not significantly affect the structure of the overall system. This doesn't mean that changes to any of the system's points or their interactions wouldn't have a significant impact on the development of the bioeconomy. To determine this, it is necessary to express the interaction of links with mathematical equations and to model this network in a dynamic way. Then it would be possible to identify how specific changes in one of the parts of the system affect the operation of the system as whole. 


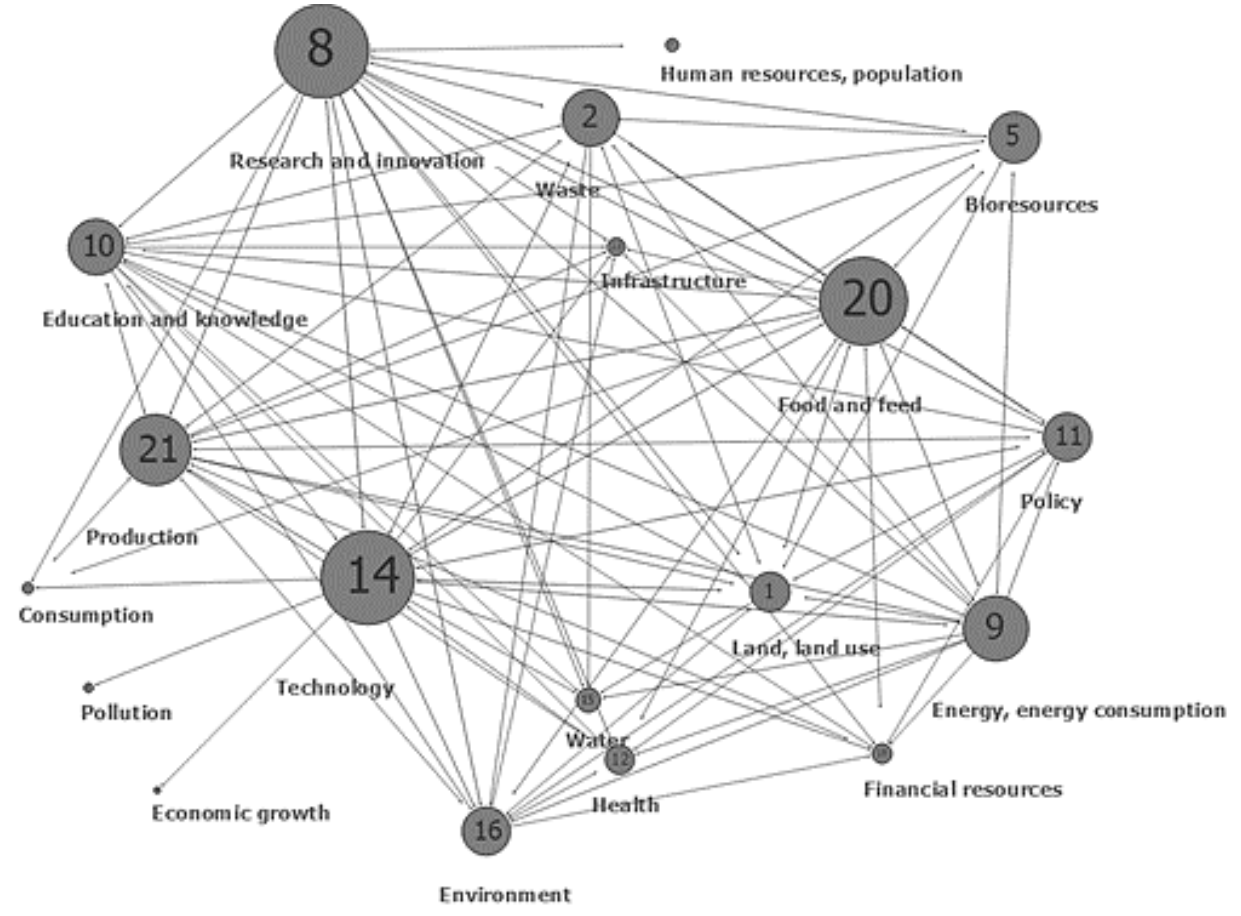

Fig. 2. Network of interactions between factors affecting the development of bioeconomy. Analysis of the media and social networks (2016-2019).

The result shows that, in the opinion of the society, the development of bioeconomy is influenced not only by many factors directly but also by the interaction of these factors. The main impact and relationship with the bioeconomy was observed for factors "technology", "research and innovation" and the interaction between these factors.

\subsection{Comparison of Networks}

In the study on the relevance and interrelation of factors affecting the development of the bioeconomy, using the bibliometric analysis method for the analysis of keywords from scientific publications in the SCOPUS database carried out earlier by the authors of this study [31], it was concluded that most studies in the context of bioeconomy are carried out in relation to factors "bioresources", "energy, energy consumption", and with the factors the weight of which is about two times smaller - "technology" and "research and innovation". While the results of this study show that in the last 3 years the media in the context of bioeconomy has focused on such factors as: "research and innovation", "technology", "food and feed", "production" and "energy, energy consumption" (Table 2). Comparing trends in scientific articles and information presented in the media shows that the weight of factors in media analysis is not as prominent as it is in scientific publications. 
TABle 2. COMPARISON OF FACTOR WeIght In MEDia ANALYSis With WEIGHT IN SCOPUS BIBLIOMETRICS ANALYSIS

\begin{tabular}{lllll}
\hline & Factor & $\begin{array}{l}\text { Weight of factor from } \\
\text { media analysis }\end{array}$ & $\begin{array}{l}\text { Weight of factor from } \\
\text { SCOPUS analysis [31] }\end{array}$ & $\begin{array}{l}\text { Weights } \\
\text { difference, \% }\end{array}$ \\
\hline 1 & Research and innovation & 0.179 & 0.118 & 34.0 \\
2 & Technology & 0.106 & 0.142 & 33.8 \\
3 & Food and feed & 0.093 & 0.019 & 79.5 \\
4 & Production & 0.075 & 0.000 & 100.0 \\
5 & Energy, energy consumption & 0.069 & 0.219 & 217.0 \\
6 & Waste & 0.060 & 0.017 & 71.7 \\
7 & Education and knowledge & 0.059 & 0.032 & 45.9 \\
8 & Bioresources & 0.054 & 0.226 & 321.2 \\
9 & Policy & 0.051 & 0.063 & 24.4 \\
10 & Environment & 0.051 & 0.024 & 52.6 \\
11 & Land, land use & 0.042 & 0.023 & 45.3 \\
12 & Health & 0.031 & 0.008 & 74.0 \\
13 & Water & 0.026 & 0.000 & 100.0 \\
14 & Financial resources & 0.021 & 0.008 & 61.8 \\
15 & Infrastructure & 0.019 & 0.000 & 100.0 \\
16 & Human resources, population & 0.014 & 0.000 & 100.0 \\
17 & Consumption & 0.012 & 0.007 & 40.5 \\
18 & Pollution & 0.010 & 0.000 & 100.0 \\
19 & Climate change & 0.008 & 0.042 & 418.5 \\
20 & Economic growth & 0.007 & 0.000 & 100.0 \\
21 & Wellbeing & 0.005 & 0.006 & 26.3 \\
22 & Behaviour & 0.004 & 0.000 & 92.6 \\
\hline 23 & Primary renewable resources & 0.003 & 0.042 & 0.0 \\
24 & Non-renewable fossil resources & 0.003 & 006 & \\
\hline & & & & \\
\hline
\end{tabular}

From the comparison of these two networks, it can be determined whether trends in science in relation to the bioeconomy have an impact on the flow of information and trends in the media and social networks. As shown in Figure 3, there is no correlation between these values. Apparently, scientific research does not have a direct influence on the opinion of the information pool, despite the fact that it forms part of the publicly available information in the network. It suggests that there is no successful knowledge transfer between scientists and society. 


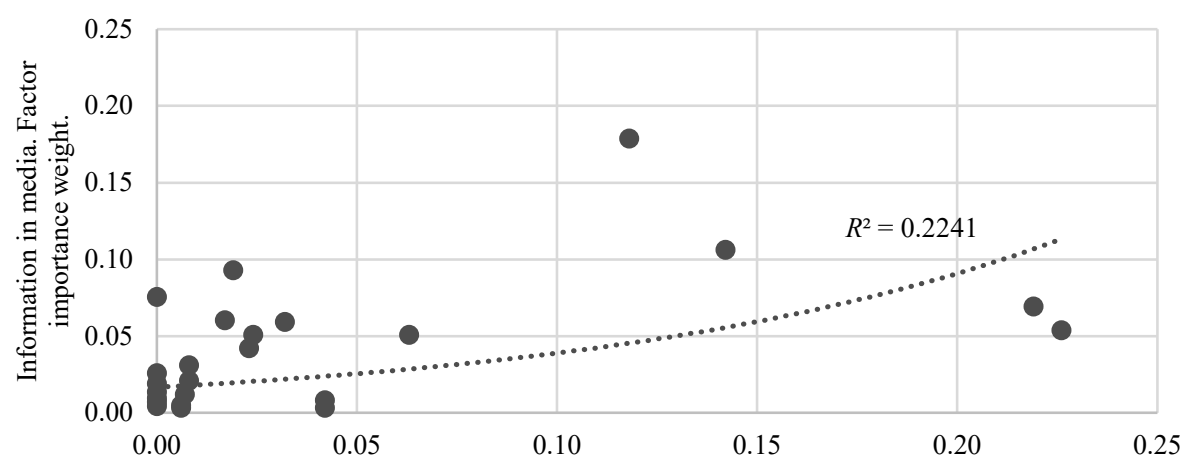

Information in SCOPUS database. Factor importance weight.

Fig. 3. Comparison of the significance of the selected factors in media and social networks with information from the SCOPUS database.

Summarizing the interaction links of the factors influencing the development of bioeconomy from both networks (Fig. 4), it is evident that the most common links are for factors "research and innovation", "energy, energy consumption" and "technology".

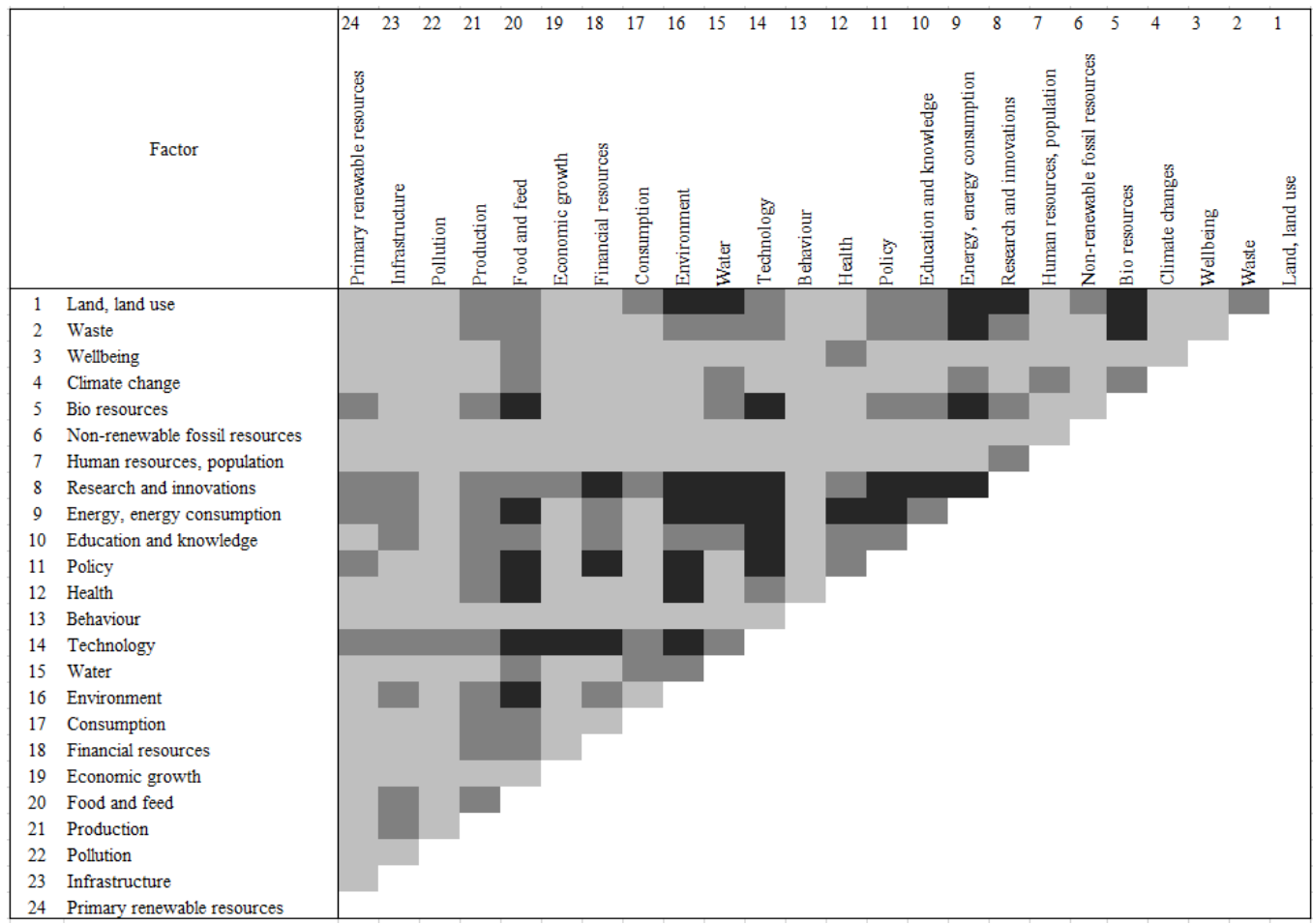

Fig. 4. Common interaction links in both networks. 
Interaction links for the "behaviour" factor do not appear in any of the networks. The fact that there are no significant direct links between the factors in the context of bioeconomy does not mean that these factors have no influence on the development of bioeconomy. In order to better determine the quantitative values of direct and indirect interactions of the factors, it is necessary to involve industry experts and evaluate their opinion. It is not excluded that the bioeconomy may be impacted through other factors or indirectly. However, most of the links appear only in one of the networks, so there is still no clarity on the relevance of the interaction of all the factors in the development of the bioeconomy.

In both types of analysis of factors affecting the development of bioeconomy, results showed that all the factors do not develop equally significant interactions and that some factors do not link to other factors at all. Therefore, there is a different density (Table 3 ) and structure for each network. The interfacing network resulting from the analysis of the media and social networks is moderately-dense, as approximately half of the potential links are significant. However, only 57 out of 190 possible links were relevant to the SCOPUS database analysis.

TABLE 3. NETWORK DENSITY

\begin{tabular}{lll}
\hline & Media analysis & SCOPUS analysis \\
\hline Nodes & 19 & 20 \\
Total possible edges & 171 & 190 \\
Edges & 89 & 57 \\
Network density & 0.5 & 0.3 \\
\hline
\end{tabular}

Of the common trends of both networks, it appears that the most important factors affecting the development of bioeconomy are "research and innovation", "technology" and "energy, energy consumption" and the interaction between these factors. Therefore, for further bioeconomy studies the authors recommend to focus on the role of these factors in the development of bioeconomy, as well as to assess the effectiveness of the implementation of different policy instruments and development scenarios.

\section{Conclusions}

Following the analysis of social networks and media, "research and innovation", "technology", "food and feed" and "production" were found to be the main factors directly related to the bioeconomy. The strongest interaction link between the factors in the context of bioeconomy is the link between the factors "research and innovation" and "technology". No significant links were identified in the context of bioeconomy for five factors: "wellbeing", "climate change", "non-renewable fossil resources", "behaviour", "primary renewable resources".

Comparing the social network and media analysis carried out in this study with the results of the previous similar study, in which scientific articles in the SCOPUS database were analysed, it can be concluded, that similar methods, while using data sources of a different nature, produce different results. Moreover, trends in scientific articles are not reflected in the generally available information stream. But there are common trends. The key factor influencing the development of the bioeconomy is the interaction between factors "research 
and innovation", "technology" and "energy, energy consumption". The interaction links with the factor "behaviour" were not determined in any of the networks.

From the results it appears that so far social aspects have not been sufficiently addressed in relation to the bioeconomy. However, there is a growing emphasis on the need for a transdisciplinary approach to research and implementation in the bioeconomy sector. There should be an increased knowledge transition between science and society as the transdisciplinarity aim is to enable mutual learning processes between science and society, therefore integrating society in research processes. As in the present study has concluded, there is presently no correlation between science and society's opinion in the context of bioeconomy.

\section{ACKNOWLEDGEMENT}

This research was supported by the Latvian Council of Science, project "Bioresources Value Model (BVM)", project number lzp-2018/1-0426.

\section{REFERENCES}

[1] European Commission. A sustainable Bioeconomy for Europe Strengthening the connection between economy, society and the environment. Updated Bioeconomy Strategy. 2018.

[2] Vivien F. D., Nieddu M., Befort N., Debref R., Giampietro M. The Hijacking of the Bioeconomy. Ecological Economics 2019:159:189-197. https://doi.org/10.1016/j.ecolecon.2019.01.027

[3] Asada R., Sern T. Competitive Bioeconomy? Comparing Bio-based and Non-bio-based Primary Sectors of the World. Ecological Economics 2018:149:120-128. https://doi.org/10.1016/j.ecolecon.2018.03.014

[4] Brunori G. Biomass, Biovalue and Sustainability: Some Thoughts on the Definition of the Bioeconomy. EuroChoices 2013:12(1):48-52. https://doi.org/10.1111/1746-692X.12020

[5] Diakosavvasi D., Frezal C. Bio-Economy and the sustainability of the agriculture and food system: opportunities and policy challenges. OECD Food, Agriculture and Fisheries Working Papers, 2018. https://doi.org/10.1787/18156797

[6] Lewandowski I. Bioeconomy: Shaping the transition to a sustainable, biobased economy. Springer, 2017. https://doi.org/10.1007/978-3-319-68152-8

[7] Zihare L., Muizniece I., Blumberga D. A holistic vision of bioeconomy: The concept of transdisciplinarity nexus towards sustainable development. Agronomy Research 2019:17(5):2115-2126. https://doi.org/10.15159/AR.19.183

[8] Pfau S. F., Hagens J. E., Dankbaar B., Smits A. J. M. Visions of sustainability in bioeconomy research. Sustainability 2014:6:1222-1249. https://doi.org/10.3390/su6031222

[9] Golembiewski B., Sick N., Bröring S. The emerging research landscape on bioeconomy: What has been done so far and what is essential from a technology and innovation management perspective? Innovative Food Science \& Emerging Technologies 2015:29:308-331. https://doi.org/10.1016/i.ifset.2015.03.006

[10] Haarich S., et al. Bioeconomy development in EU regions. Mapping of EU Member States'/regions' Research and Innovation plans \& Strategies for Smart Specialisation (RIS3) on Bioeconomy for 2014-2020. Spatial Foresight, SWECO, OIR, t33, Nordregio, Berman Group, Infyde, 2017. https://doi.org/10.2777/84684

[11] Schütte G. What kind of innovation policy does the bioeconomy need? New Biotechnology 2017:40(A):82-86. https://doi.org/10.1016/j.nbt.2017.04.003

[12] Konstaninis A., Rozakis S., Efpraxia-Aithra M., Kesheng S. A Definition of Bioeconomy though the Bibliometrics Networks of the Scientific Literature. AgroBioForum 2018:21(2):64-85.

[13] Muizniece I., Kubule A., Blumberga D. Towards understanding the transdisciplinary approach of the bioeconomy nexus. Energy Procedia 2018:147:75-180. https://doi.org/10.1016/j.egypro.2018.07.052

[14] Lehtonen M. The environmental-social interface of sustainable development: capabilities, social capital, institutions. Ecological Economics 2004:49(2):199-214. https://doi.org/10.1016/j.ecolecon.2004.03.019

[15] Bracco S., Tani A., Çalıcıoğlu Ö., Gomez San Juan M., Bogdanski A. Indicators to monitor and evaluate the sustainability of bioeconomy. Overview and a proposed way forward. Rome: FAO, 2019.

[16] Ramcilovic-Suominen S., Pülzl H. Sustainable development - A 'selling point' of the emerging EU bioeconomy policy framework? Journal of Cleaner Production 2018:172(20):4170-4180. https://doi.org/10.1016/j.jclepro.2016.12.157

[17] Bugge M., Hansen T., Klitkou A. What is the bioeconomy? A review of the literature. Sustainability 2016:8(7):691. https://doi.org/10.3390/su8070691

[18] Mittra J., Zoukas G. Unpacking the Concept of Bioeconomy: Problems of Definition, Measurement, and the Attribution of Value. Science \& Technology Studies 2020:33(1):2-21. https://doi.org/10.23987/sts.69662 
[19] Sanz-Hernández A., Esteban E., Garrido P. Transition to a bioeconomy: Perspectives from social sciences. Journal of Cleaner Production 2019:224:107-119. https://doi.org/10.1016/j.jclepro.2019.03.168

[20] Braun J. Bioeconomy - The global trend and its implications for sustainability and food security. Global Food Security 2018:19:81-83. https://doi.org/10.1016/j.gfs.2018.10.003

[21] Urmetzer S., Lask J., Vargas-Carpintero R., Pyka A. Learning to change: Transformative knowledge for building a sustainable bioeconomy. Ecological Economics 2020:167:106435. https://doi.org/10.1016/j.ecolecon.2019.106435

[22] Hasenheit M., Gerdes H., Kiresiewa Z., Beekman V. Summary report on the social, economic and environmental impacts of the bioeconomy. 2016.

[23] Falcone P. M., Garcia S. G., Imbert E., Lijo L., Moirea M. T., Tani A., Tartiu V. E., Morone P. Transitioning towards the bio-economy: Assessing the social dimension through a stakeholder lens. Corporate Social Responsibility and Environmental Management 2019:26(5):1135-1153. https://doi.org/10.1002/csr.1791

[24] Vainio A., Ovaska U., Varho V. Not so sustainable? Images of bioeconomy by future environmental professionals and citizens. Journal of Cleaner Production 2019:210:1396-1405. https://doi.org/10.1016/j.jclepro.2018.10.290

[25] Wohlfahrt J., Ferchaud F., Gabrielle B., Godard C., Kurek B., Loyce C. Therond O. Characteristics of bioeconomy systems and sustainability issues at the territorial scale. A review. Journal of Cleaner Production 2019:232:898-909. https://doi.org/10.1016/j.jclepro.2019.05.385

[26] Sanz-Hernández A., Sanagustín-Fons M. V., López-Rodríguez M. E. A transition to an innovative and inclusive bioeconomy in Aragon, Spain. Environmental Innovation and Societal Transitions 2019:33:301-316. https://doi.org/10.1016/j.eist.2019.08.003

[27] Pinto S., Albanese F., Dorso C. O., Balanzuela P. Quantifying time-dependent Media Agenda and public opinion by topic modelling. Physica A: Statistical Mechanics and its Applications 2019:524:614-624.

[28] McCombs M., Shaw D. L. The agenda-setting function of mass media. Public Opinion Quarterly 1972:36(2):176-187. https://doi.org/10.1086/267990

[29] Choi J., Han Y., Kim Y. A Research for Finding Relationship Between Mass Media and Social Media Based on Agenda Setting Theory. In: Lee R. (Eds.) Software Engineering Research, Management and Applications. Studies in Computational Intelligence. Springer, Cham, 2016:654. https://doi.org/10.1007/978-3-319-33903-0_8

[30] Klašnja M., Barberá P., Beauchamp N., Nagler J., Tucker J. A. Measuring Public Opinion with Social Media Data. Oxford Handbooks Online, 2017. https://doi.org/10.1093/oxfordhb/9780190213299.013.3

[31] Muizniece I., Zihare L., Blumberga D. Obtaining the factors affecting bioeconomy. Environmental and climate technologies 2019:23(1):277-291. https://doi.org/10.2478/rtuect-2019-0018

[32] Podobnik V., Lovrek I. Implicit Social Networking: Discovery of Hidden Relationships, Roles and Communities among Consumers. Procedia Computer Science 2015:60:583-592. https://doi.org/10.1016/j.procs.2015.08.185

[33] Giurca A., Metz T. A social network analysis of Germany's wood-based bioeconomy: Social capital and shared beliefs. Environmental Innovation and Societal Transitions 2018:26:1-14. https://doi.org/10.1016/j.eist.2017.09.001

[34] Bauer F., Hansen T., Hellsmark H. Innovation in the bioeconomy - dynamics of biorefinery innovation networks. Technology Analysis \& Strategic Management 2018:30(8):1-13. https://doi.org/10.1080/09537325.2018.1425386

[35] Adams J., Hilier-Brown C. H., Moore J. H., Lake A. A., Araujo-Soares V., White M., Summerbell C. Searching and synthesising 'grey literature' and 'grey information' in public health: critical reflections on three case studies. Systematic Reviews 2016:5(164):1-11. https://doi.org/10.1186/s13643-016-0337-y 